\title{
The effect of colchicine on alveolar bone loss in ligature-induced periodontitis
}

\section{Hulya TOKER(a) \\ Hatice BALCI YUCE(b) \\ Ali YILDIRIM(a) \\ Mehmet Buğrul TEKiN(a) \\ Fikret GEVREK ${ }^{(\mathrm{c})}$}

(a) Cumhuriyet University, School of Dentistry, Department of Periodontology, Sivas, Turkey.

(b)Gaziosmanpaşa University, School of Dentistry, Department of Periodontology, Tokat, Turkey

(c)Gaziosmanpaşa University, School of Medicine,Department of Histology and Embryology, Tokat, Turkey

Declaration of Interests: The authors certify that they have no commercial or associative interest that represents a conflict of interest in connection with the manuscript.

Corresponding Author:

Hulya Toker

E-mail: tokerhulya@gmail.com

https://doi.org/10.1590/1807-3107bor-2019.vol33.0001

December 07, 2017

Accepted for publication: October 16, 2018

Last revision: November 12, 2018

\begin{abstract}
Colchicine is widely used in the treatment of several inflammatory diseases due to its anti-inflammatory effect, but effects on bone metabolism are unclear. The aim of this study was to evaluate the effects of systemically-administered colchicine on healthy periodontium and experimentally-induced periodontitis. In total, 42 male Wistar rats were included in this study. A non-ligated group constituting the negative control group (Control, $\mathrm{C}, \mathrm{n}=6$ ) and a ligature-only group forming the positive control group $(\mathrm{LO}, \mathrm{n}=12)$ were created separately. Twelve rats were treated with $0.4 \mathrm{mg} / \mathrm{kg}$ colchicine and another 12 with $1 \mathrm{mg} / \mathrm{kg}$ colchicine. In the colchicine-administered groups, right mandibles constituted the ligated groups $(1 \mathrm{mgC}-\mathrm{L}$ or $0.4 \mathrm{mgC}-\mathrm{L})$ and left mandibles formed the corresponding non-ligated controls $(1 \mathrm{mgC}$ or $0.4 \mathrm{mgC})$. Silk ligatures were placed at the gingival margin of the lower first molars. The animals were euthanized at different time-points of healing (11 or 30 days). Alveolar bone loss was clinically measured and TRAP+ osteoclasts, osteoblastic activity, and MMP-1 expression were examined histologically. There was no increase in alveolar bone loss with either colchicine dose in healthy periodontium $(p>0.05)$ and the highest level of alveolar bone loss, TRAP+ osteoclast number, and MMP-1 expression were measured in the LO group $(\mathrm{p}<0.05)$. The $0.4 \mathrm{mgC}-\mathrm{L}$ group showed less alveolar bone loss at 11 days $(\mathrm{p}<0.05)$, but greater loss at 30 days. The $1 \mathrm{mgC}-\mathrm{L}$ group showed higher osteoblast number than the other ligated groups $(p<0.05)$ at both time-points. In summary, colchicine did not increase alveolar bone loss in healthy periodontium and also may tend to reduce periodontitis progression. However, further extensive study is necessary to understand the mechanism of colchicine action on alveolar bone loss in periodontitis.
\end{abstract}

Keywords: Periodontitis; Alveolar Bone Loss; Colchicine.

\section{Introduction}

Periodontitis is a chronic inflammatory disease caused by a pathogenic microbiota in the subgingival biofilm. Bacterial challenge induces an inflammatory reaction with an increase in cytokines, prostaglandins, and reactive oxygen species. ${ }^{1,2}$ Sustained inflammation in the tissue progresses into deep tissues and causes loss of supporting connective tissue and 
alveolar bone. Continued inflammation also causes the formation of a periodontal pocket, ultimately leading to tooth loss. ${ }^{3}$ However, it is now known that the underlying tissue damage observed in this disease results from an excessive immune response to subgingival pathogens. ${ }^{4}$ Therefore, it follows that pharmacological inhibition of host response pathways may be an adjunctive or alternative strategy for treating periodontal disease. ${ }^{5}$

Colchicine, originally extracted from Colchicum autumnale, is an anti-inflammatory drug that has been in continuous use for more than 3,000 years. ${ }^{6}$ Colchicine acts by binding tubulin in a poorly reversible manner, forming a colchicine-tubulin complex. At lower doses, this complex interferes with microtubule formation and elongation, and at higher concentrations promotes microtubule depolymerization. ${ }^{7}$ Classically, it was thought that the microtubule disruption caused by colchicine led to anti-inflammatory effects by inhibiting neutrophil chemotaxis, diminishing release of lysosomal enzymes during phagocytosis, inhibiting the expression of adhesion molecules on the surface of endothelial cells and leukocytes and also inhibiting inflammasome activation within macrophages. ${ }^{8,9,10,11}$ In addition, colchicine depresses neutrophil degranulation, which is closely related to the secretory response and oxidative outbreak ${ }^{12,13}$ and colchicine has been shown to attenuate lipid peroxidation and stabilize membranes. ${ }^{14}$ Colchicine has also been prescribed for acute gout attacks and prophylaxis, Behcet's Disease ${ }^{15}$, familial Mediterranean fever (FMF), pseudo-gout and dermatologic disorders, due to its aforementioned effects. ${ }^{16}$

While the anti-inflammatory activity of colchicine is well known, its effect on bone metabolism is unclear. Earlier studies suggested that colchicine decreased osteoclast number and blocked resorption in bones pretreated with parathyroid hormone. ${ }^{17}$ Conversely, a recent study reported that prolonged colchicine treatment $(1 \mathrm{mg} / \mathrm{kg} /$ day for 6 weeks) had a significant negative influence on fracture healing in rat tibia, by inhibiting fracture union and reducing bone strength. ${ }^{18}$ In addition, in a recent clinical study that investigated the association between FMF and osteoporosis in adult patients, they found that regular colchicine treatment, which might have suppressed the inflammatory status of FMF, may not prevent the development of osteoporosis. ${ }^{19}$ However, to the best of our knowledge, there are no data regarding the effects of colchicine on alveolar bone loss in periodontitis. Also, whether colchicine can ameliorate or reduce periodontitis progression remains unknown. Consequently, the aim of this study was to investigate the effect of colchicine, which has anti-inflammatory and anti-oxidative effects, on healthy periodontium and alveolar bone resorption in a rat model of experimental periodontitis, both histopathologically and histomorphometrically.

\section{Methodology}

\section{Animals and experimental model}

This study was approved by the Ethical Committee for Animal Studies of Cumhuriyet University School of Medicine. In total, 42 male Wistar rats (weighing 230-250 g) were used in the experiment. Rats were housed in individual cages in a room with $12 \mathrm{~h}$ lightdark cycles, with water and food available ad libitum.

This study used a split-mouth design to study ligated groups with or without systemic administration of colchicine, with the experimental conditions on one side, and the control on the other. In each rat, a ligature was placed around their right first molar while the contralateral left first molar did not have a ligature as a colchicine control. The animals were divided into groups as follows:

a. Non-ligated controls (control) (6 rats);

b. Ligature-only (LO) group (12 rats);

c. Colchicine $0.4 \mathrm{mg} / \mathrm{kg} /$ day - nonligated $(0.4 \mathrm{mgC})$ group (left side) and ligated (0.4 mgC-L) group (right side) (12 rats);

d. Colchicine $1 \mathrm{mg} / \mathrm{kg} /$ day nonligated $(1 \mathrm{mgC})$ group (left side) and ligated (1 mgC-L) group (right side) (12 rats).

\section{Induction of experimental periodontitis}

The procedure was carried out under general anesthesia using $40 \mathrm{mg} / \mathrm{kg}$ Ketamine hydrochloride. A 4-0 silk suture was sub-marginally placed around the first molars of the right mandibular quadrants. All ligatures were positioned subgingivally and lost or 
loose sutures were replaced. All ligature placements were performed by the same operator (A.Y.).

Colchicine was prepared as doses of $0.4 \mathrm{mg} / \mathrm{kg}$ and $1 \mathrm{mg} / \mathrm{kg}$ in $0.5 \mathrm{~mL}$ distilled water and systemically administered by gastric feeding at a rate of $0.5 \mathrm{~mL}$ daily until sacrifice. Colchicine doses used by studies were in the range from $0.1 \mathrm{mg} / \mathrm{kg}$ to $1 \mathrm{mg} / \mathrm{kg}$. And the doses of colchicine were selected based on the doses studies in previous studies which were shown to be effective. ${ }^{20,21,22,23}$ In colchicine groups, half of the animals of each group were sacrificed at 11 days and the remainder at 30 days. Both of these durations are considered to be a suitable time period to observe periodontal disease course in rats. ${ }^{24,25,26,27}$

\section{Alveolar bone measurements}

After sacrifice, mandibles were harvested and soft tissues around the mandibles were excised. The mandibles were stained with $1 \%$ aqueous methylene blue to identify the cementoenamel junction (CEJ). The distance between the CEJ and the alveolar crest was measured at $16 \times$ magnification using digital imaging software (Zeiss, Stemi 2000, Oberkochen, Germany) integrated with a stereomicroscope and camera system. All measurements were performed at six points, three buccal and three lingual surfaces, and a mean value for each tooth was calculated. The morphometric measurement of alveolar bone loss was performed by a single examiner (M.B.T.) who was unaware of the identity of the samples.

\section{Histopathological evaluation}

After stereomicroscopic analysis, right and left mandibles were immersed in $10 \%$ neutral buffered formalin for $48 \mathrm{~h}$. Decalcification of the mandibles was performed with EDTA solution (10\%, for 10 weeks). After decalcification, all samples were dehydrated through an ethanol series and embedded in paraffin, then $5 \mu \mathrm{m}$ serial sections were prepared and used for hematoxylin and eosin (H\&E) and tartrate-resistant acid phosphatase (TRAP) histochemical staining. The stained sections were evaluated by light microscopy (Eclipse E 600; Nikon, Tokyo, Japan).

Cuboid osteoblast cells bordered with osteoid and neighboring periodontal ligament and visible on active bone formation surfaces were considered to be active osteoblast cells and counted. Inflammatory cell infiltration (ICI) of the periodontal tissue was also evaluated in all sections. Total inflammatory cells in an area of $10,000 \mu \mathrm{m}^{2}$ (neutrophils, lymphocytes, eosinophils, and macrophage cells) were counted at 1,000× magnification. A single examiner (F.G.) who was also unaware of the identity of the samples, performed all histological evaluations.

\section{TRAP histochemistry}

Osteoclast cells were identified by TRAP staining on decalcified sections. The TRAP histochemistry procedure was performed according to Leong's protocol..$^{28}$ Specimens were rehydrated and treated with a mixture of sodium acetate $(0.2 \mathrm{M})$ and sodium tartrate dibasic dehydrate. Sections were incubated in this solution for $20 \mathrm{~min}$ at room temperature. After incubation, fast red TR salt and naphthol AS-MX phosphate were added and a second incubation for $1 \mathrm{~h}$ at $37^{\circ} \mathrm{C}$ was performed. During the second incubation, after the first $30 \mathrm{~min}$, sections were closely monitored under a light microscope. Once the TRAP+ osteoclast cells were stained bright red, the procedure was stopped and sections were washed and stained with Gill's hematoxylin.

\section{MMP-1 Immunohistochemistry}

MMP-1 immunohistochemistry was performed in order evaluate collagen breakdown. After deparaffinization and dehydration of the sections, antigen retrieval was performed using $10 \mathrm{mM}$ sodium citrate buffer $\left(\mathrm{pH} \mathrm{6.0)}\right.$ for $2 \mathrm{~h}$ at $70^{\circ} \mathrm{C}$. Then the sections were treated with $3 \%$ hydrogen peroxide to quench endogenous peroxidase activity. After incubation with normal rabbit serum for $30 \mathrm{~min}$, samples were incubated with primary antibodies overnight. Sections were then washed five times with phosphate buffered saline then incubated with biotinylated immunoglobulin $\mathrm{G}$ for $30 \mathrm{~min}$, washed several times with phosphate-buffered saline and reacted with a streptavidin-horseradish peroxidaseconjugated reagent for $30 \mathrm{~min}$. Following three 5-minute washes with phosphate-buffered saline, samples were incubated with AEC chromogen to visualize the immunoreactivity, then counterstained with hematoxylin and analyzed using light microscopy. 


\section{Immunohistochemical H-score analysis}

Five areas were selected randomly from the sections from each animal to be examined, under a light microscope with 1,000× magnification. Categorical enumeration of the cells within these areas was made according to their immune staining intensity. All cells in an area of $10,000 \mu \mathrm{m}^{2}$ were counted considering the staining intensities. During these counts, both the number of cells showing positive immunoreactivity and the degree of immunoreactive intensity of these cells, as well as the total number of cells which were stained and not stained were considered. No staining was considered as score ' 0 ', slight staining intensity was ' 1 ', mild staining intensity was ' 2 ' and strong staining intensity was ' 3 '. The average of the results of a blind study was taken. To estimate the results of the counts, the H Score formula $\left[\sum \mathrm{Pi}(\mathrm{i}+1)\right]$ was used. In this formula, I represents the staining intensity score and Pi represents the percentage of stained cells.

\section{Statistical analysis}

Data are presented as mean \pm SD or percentage as appropriate. Statistical analyses were performed with SPSS $®$ software (vs.23.00). Osteoclast numbers, alveolar bone loss, osteoblast numbers, and MMP-1 H-score were evaluated by the Kruskal-Wallis and Man-Whitney-U tests for pair-wise comparisons. $P$ values $<0.05$ were considered statistically significant.

\section{Results}

Experimental periodontitis was successfully achieved and ligation caused periodontal destruction and alveolar bone loss around mandibular first molar teeth. The animals did not show any obvious signs of systemic illness throughout the study period and no rats were lost or excluded from the study.

\section{Morphometric analyses}

The highest level of alveolar bone loss was measured in the LO group at 11 days $(p<0.05)$ (Figure 1 and 2). There was no significant difference in alveolar bone loss among all control groups. Furthermore, alveolar bone loss was similar in both colchicine groups with a ligature $(p>0.05)$, and only systemic administration of $0.4 \mathrm{mg}$ colchicine decreased alveolar bone loss ( $\mathrm{p}<0.05)$.

According to analyses at 30 days, there was no significant difference among all control groups $(p>0.05)$. Although the alveolar bone loss in both colchicine groups was lower than in the L group, the differences were not significant ( $\mathrm{p}>0.05$ ). However, at 30 days, alveolar bone loss was increased in the $0.4 \mathrm{mgC}-\mathrm{L}$ group compared to at 11 days $(\mathrm{p}<0.05)$.

\section{Histopathological analyses}

Figure 3 shows a representative histological view of the groups. The TRAP-positive osteoclast number in the L group was higher than in either of the colchicine groups with a ligature, but the difference was not significant at 11 days $(p>0.05)$ (Figure 4). In addition, the osteoclast number in the L group was higher than in all control groups. The other comparisons showed no significant differences regarding osteoclast numbers at 11 days.

At 30 days, osteoclast numbers in the $L$ and 1mg-L groups were higher than in any of the controls (Figure 3 II-B). Also, the 1mg-L group was found to contain significantly higher osteoclast numbers than the $0.4 \mathrm{mg}$-L group, but the differences were not significant. Among the control groups, there were no significant differences in osteoclast numbers at 30 days, nor were there any significant differences between 11 and 30 days. In contrast, in the L group, there were significant differences between 11 and 30 days in terms of osteoclast number $(\mathrm{p}<0.05)$.

ICI was higher in all ligated groups than in the non-ligated controls at either 11 or 30 days $(p<0.05)$. There were no significant differences among all controls in terms of ICI at either time-point $(p>0.05)$. In addition, there were significant differences in ICI between the $0.4 \mathrm{mgC}-\mathrm{L}$ and the $\mathrm{L}$ group at 11 days. However, at 30 days, there were no statistically-significant differences in ICI among ligated groups.

According to histological analyses, osteoblast numbers were similar among all control groups and no significant difference was observed (Figure 5). Likewise, there were no significant differences in osteoblast numbers between $\mathrm{L}$ and $0.4 \mathrm{mg}$-L groups $(p>0.05)$ (Figure 3 III-B). However, osteoblast numbers 


\section{A}
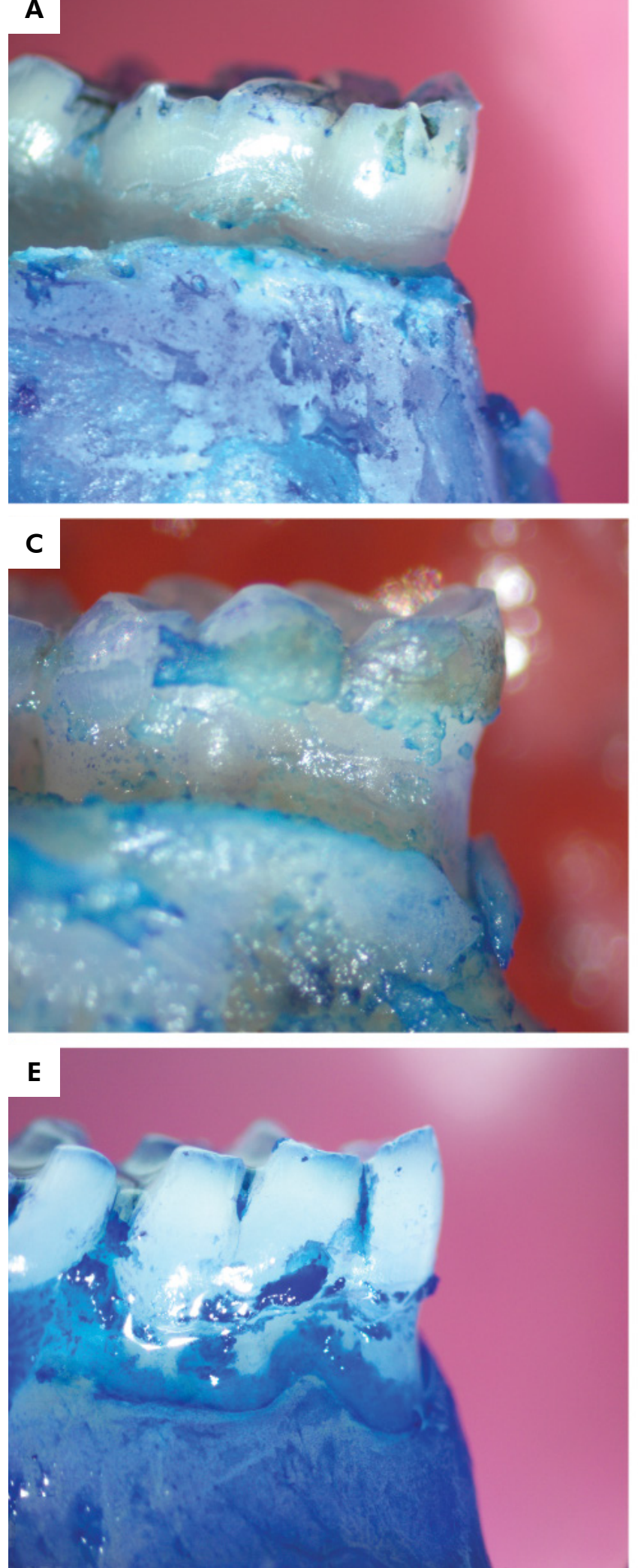

B

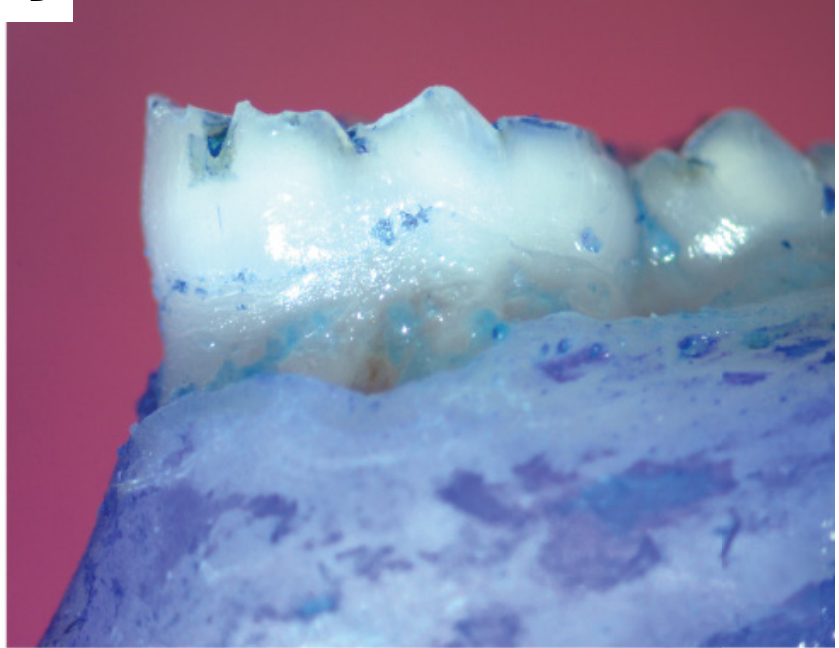

D

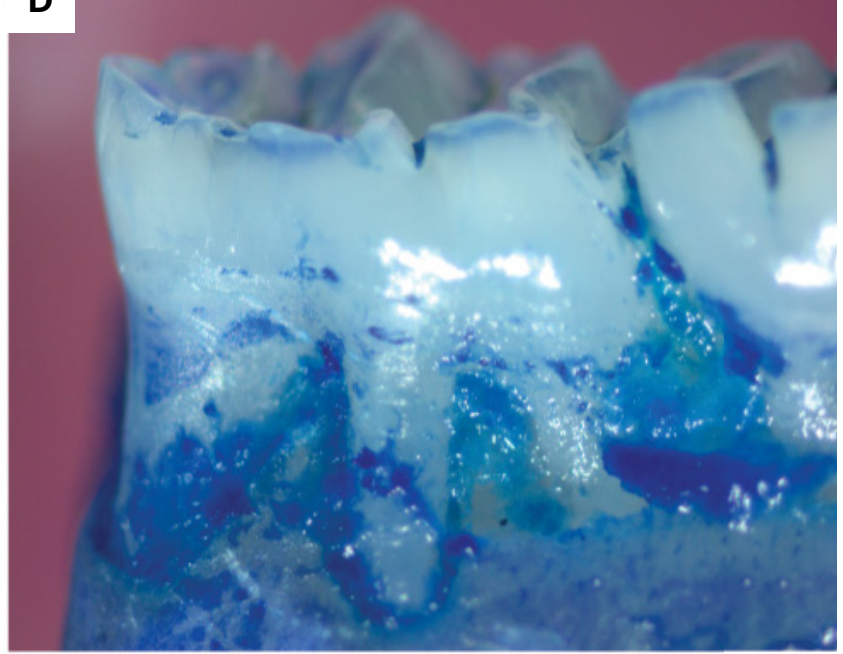

F

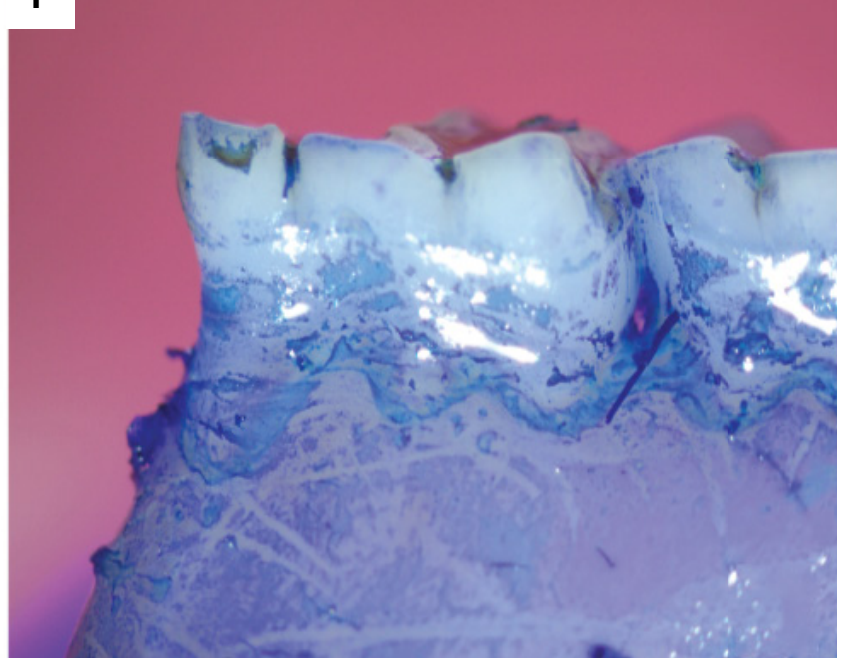

Figure 1. Representative photographs of the alveolar bone loss in the mandibular first molar tooth in the Control (A), $0.4 \mathrm{mgC}$ $(B), 1 \mathrm{mgC}(\mathrm{C})$, LO (D), $0.4 \mathrm{mgC}-\mathrm{L}(\mathrm{E})$, and $1 \mathrm{mgC}-\mathrm{L}(\mathrm{F})$ groups at 30th day. 
in the $1 \mathrm{mg}$-L group were higher than in the L group at 11 days $(\mathrm{p}<0.05)$.

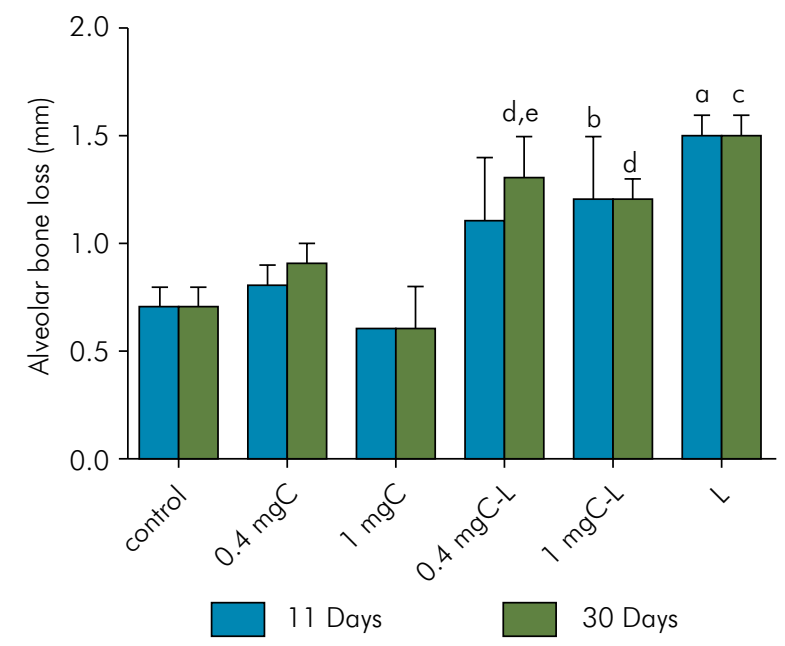

${ }^{a} \mathrm{p}<0.05$ vs. all controls and $0.4 \mathrm{mgC}-\mathrm{L}$ groups at 11 days; ${ }^{b} \mathrm{p}<0.05$ vs. $C$ and $1 \mathrm{mgC}$ groups at 11 days, ${ }^{c} p<0.05$ vs. all controls at 30 days; ${ }^{d} p<0.05$ vs. $C, 1 \mathrm{mgC}$ group at 30 days, ${ }^{\mathrm{e}} \mathrm{p}<0.05$ vs. $0.4 \mathrm{mgC}-\mathrm{L}$ at 11 days

Figure 2. Mean alveolar bone loss of study groups.
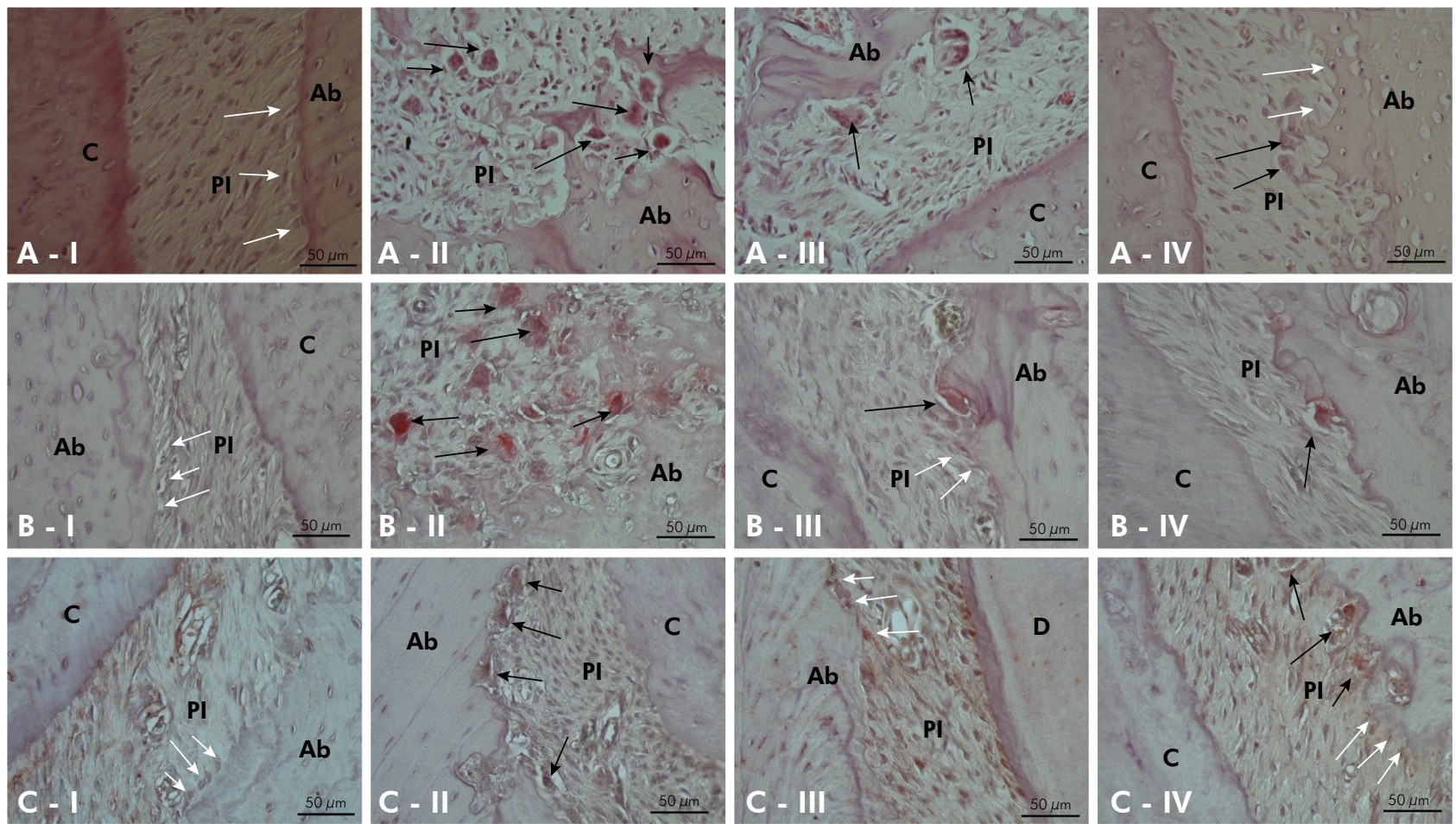

I: Non-ligated control group; II: Ligated group (30 days); III: ligated and $0.4 \mathrm{mg} / \mathrm{kg}$ colchicine administered group (30 days); IV: Ligated and $1 \mathrm{mg} / \mathrm{kg}$ colchicine administered group (30 days); Ab: alveol bone; c: cement; D: dentin; Pl: periodontal ligament. Black arrows show osteoclast cells and white arrows show osteoblast cells.

Figure 3. Representative samples of TRAP, hematoxylin and MMP-1 -stained periodontium from Wistar rats. A: TRAP staining (400x magnification), B: Hematoxylin staining (400x magnification) and C: MMP-1 staining (400x magnification). 


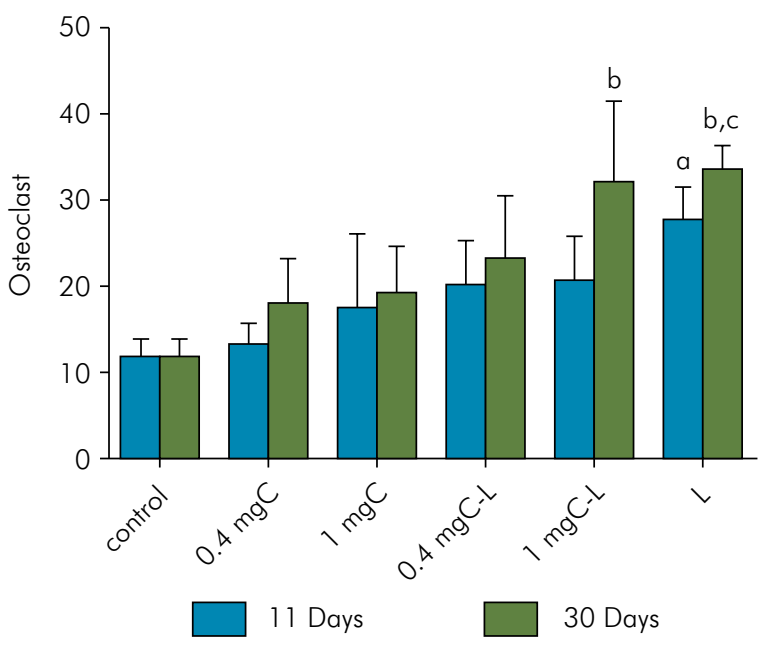

${ }^{a} p<0.05$ vs. all controls at 11 days, ${ }^{b} p<0.05$ vs. all controls at 30 days, ${ }^{c} p<0.05$ vs. $L$ group at 11 days

Figure 4. TRAP + osteoclast numbers in experimental groups and controls (mean \pm SD).

\section{Discussion}

This study is the first to evaluate the effect of colchicine on experimental periodontitis and alveolar bone tissue. We have demonstrated that systemically-administered colchicine does not increase alveolar bone loss at either dose and after either term in healthy periodontium. In addition, we found that colchicine tends to decrease alveolar bone loss by increasing osteoblastic activity and decreasing osteoclastic activity in ligature-induced periodontitis.

The ligature method has been extensively used for induction of experimental periodontitis. ${ }^{29,30}$ In this method, ligation triggers an inflammatory reaction caused by an accumulation of bacterial plaque around the first molar tooth. ${ }^{26}$ In the present study, ligature placement on the first molar tooth caused a significant amount of bone loss at day 11 and 30. The eleven day and 30 day time periods are considered to be suitable time periods to observe early and late progress of the disease and treatment, relatively. ${ }^{24,25,26,27}$ However, for every animal model of a human disease, there are inherent limitations. Molars in rats are similar in anatomic configuration and structure to human molars, but the experimental model used is that the induced periodontitis follows an acute course, during which tissue trauma and adjacent microbial

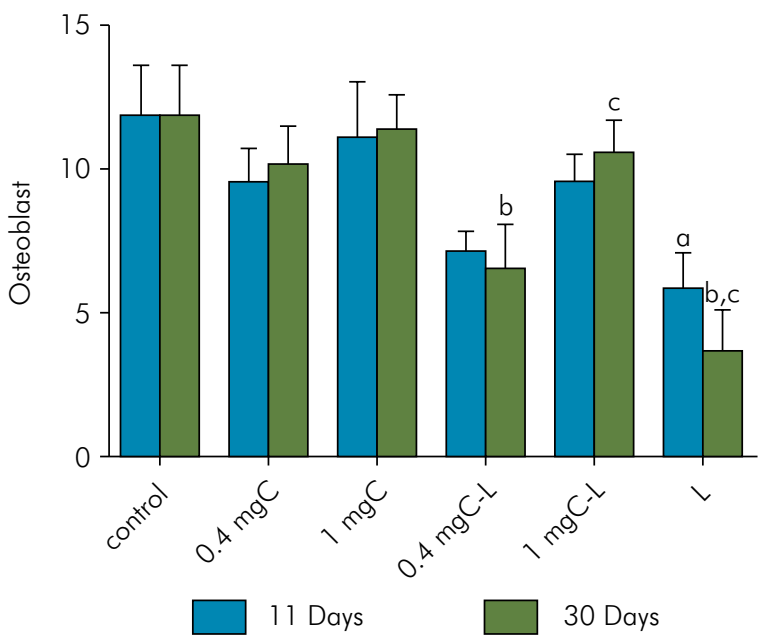

${ }^{a} \mathrm{p}<0.05$ vs. all controls and $1 \mathrm{mgC}-\mathrm{L}$ at 11 days; ${ }^{b} \mathrm{p}<0.05$ vs. the other groups at 30 days; ${ }^{c} p<0.05$ vs. 11 days

Figure 5. Mean osteoblast numbers in the study groups.

accumulation accelerate the destructive process. Such pathways of acute inflammation are likely to differ from those involved in chronic periodontitis.

Colchicine is currently being used confidently in several diseases due to its anti-inflammatory effect. ${ }^{31-32}$ In a recent experimental study which investigated the effects of colchicine, a microtubule-disrupting agent, on skeletal muscle ischemic injury in rats, the authors suggested that $1 \mathrm{mg} / \mathrm{kg}$ colchicine significantly decreased levels of malondialdehyde, TNF- $\alpha$, and IL-1 $\beta$ and increased superoxide dismutase in ischemic tissues. ${ }^{33}$ In addition, at higher doses colchicine exerts various other inflammatory effects including suppression of phospholipase A2 activation, lysosomal enzyme release, and phagocytosis. ${ }^{34-35}$ However, in our study, inflammatory status was evaluated histologically and MMP-1 expression Inflammatory cell infiltration was increased in all ligated groups due to the presence of ligatures. However, colchicine administration, especially at a dose of $0.4 \mathrm{mg} / \mathrm{kg}$, decreased ICI activity at 11 days but this effect was not seen at 30 days.

MMP-1 and -8 belong to the collagenase group of the MMP family, and it has been reported that both MMP-1 and -8, the major interstitial collagenases, degrade the extracellular matrix in periodontal disease and are mainly secreted by neutrophils. ${ }^{36}$ In addition, MMP-1 may preferentially affect the 
initiation of collagen destruction compared to MMP-8. Further, several reports have shown that MMP levels are higher in periodontitis, compared to gingivitis and healthy individuals. ${ }^{37-38}$ In our study, the highest expression of MMP-1 was observed in the ligature only group and the expression decreased in groups with systemically-administered colchicine. Furthermore, there was no significant effect on healthy periodontium at the evaluated doses. However, Nahm et al. found contradictory effects, reporting that colchicine-treated periodontal ligament fibroblasts significantly increased the expression of MMP-1 in a time-dependent manner compared with the controls and also showed a time-dependent increase in TIMP-1 and TGF-beta1 expression. ${ }^{39}$

Several clinical studies have been conducted to investigate the association between bone metabolism and colchicine, but contradictory results have been found. Suyani et al. investigated the association between FMF and osteoporosis in adult patients who were taking regular colchicine. ${ }^{19}$ They found that total femur $\mathrm{T}$ scores were significantly lower in FMF patients compared to healthy controls. They also suggested that subclinical inflammation may be associated with decreased bone mineral content in these patients. In contrast, Siverekli et al. ${ }^{40}$ suggested that no significant difference was found between FMF and healthy controls regarding bone density. In our study, osteoclast numbers were higher in the ligature only group than any others during the study period. Colchicine treatment reduced osteoclast number to control levels by 11 days, and did not cause any alveolar bone loss in the periodontium. Similarly, the results of our previous clinical study suggested that patients with FMF, who regularly used colchicine, did not manifest higher attachment loss compared to age- and sex-matched systemically-healthy controls. ${ }^{41}$

\section{References}

1. Ford PJ, Gamonal J, Seymour GJ. Immunological differences and similarities between chronic periodontitis and aggressive periodontitis. Periodontol 2000. 2010 Jun;53(1):111-23. https://doi.org/10.1111/j.1600-0757.2010.00349.x
In an earlier study made by Arai et al., they reported that colchicine treatment at a dose $1 \mathrm{mg} / \mathrm{kg}$ intravenously revealed high levels of type I collagen mRNA expression in osteoblasts of the mineralized ectopic surface during the bone period and formed trabecular bone-like ectopic calcified tissue. ${ }^{42}$ Furthermore, in that study osteocalcin showed no specific signals throughout the experiments but osteopontin mRNA was expressed especially in the initial phase of ectopic bone resorption. However, Salai et al. reported that colchicine is an in vitro inhibitor of proliferation of osteoblasts, causing a marked decrease in tissue mineralization..$^{43}$ Also, they suggested that colchicine at low concentrations, of up to $3 \mathrm{ng} / \mathrm{mL}$, has the capacity to selectively inhibit mineralization by bone-like cell ins culture, without affecting osteoblast cell proliferation. Conversely, we found that osteoblastic activity was less frequently seen in the ligature-only group and showed higher activity and numbers in colchicine groups, especially at a dose of $1 \mathrm{mg}$.

There are certain limitations to the present study. As the exact mechanism underlying the anti-inflammatory effect of colchicine in periodontitis is not clear, we evaluated limited parameters in the present study, only evaluating MMP-1 levels and inflammatory cell counts in histological sections as markers of inflammation. Changes in the expression of bone-specific markers such as RANKL and osteoprotegerin must be investigated.

In conclusion, within the inherent limitations of this animal study, we found that colchicine exerted an anti-inflammatory effect on periodontitis progression in ligature-induced periodontitis without affecting healthy periodontium. However, further studies are warranted to investigate the long-term efficacy and mode of action of colchicine on alveolar bone loss and inflammation in periodontitis because of its extensive use in several inflammatory diseases.
2. Pihlstrom BL, Michalowicz BS, Johnson NW.

Periodontal diseases. Lancet.

2005 Nov;366(9499):1809-20.

https://doi.org/10.1016/S0140-6736(05)67728-8 
3. Hernández M, Dutzan N, García-Sesnich J, Abusleme

L, Dezerega A, Silva $N$ et al. Host-pathogen

interactions in progressive chronic periodontitis.

J Dent Res. 2011 Oct;90(10):1164-70.

https://doi.org/10.1177/0022034511401405

4. Hajishengallis $G$. The inflammophilic character of the periodontitis-associated microbiota. Mol Oral Microbiol. 2014 Dec;29(6):248-57. https://doi.org/10.1111/omi.12065

5. Caton J, Ciancio S, Crout R, Hefti A, Polson A, editors. Adjunctive use of subantimicrobial doxycycline therapy for periodontitis. J Dent Res. 1998;77:1101.

6. Hartung EF. History of the use of colchicum and related medicaments in gout; with suggestions for further research. Ann Rheum Dis. 1954 Sep;13(3):190-200. https://doi.org/10.1136/ard.13.3.190

7. Bhattacharyya B, Panda D, Gupta S, Baneriee M. Anti-mitotic activity of colchicine and the structural basis for its interaction with tubulin. Med Res Rev. 2008 Jan;28(1):155-83. https://doi.org/10.1002/med.20097

8. Misawa T, Takahama M, Kozaki T, Lee H, Zou J, Saitoh T et al. Microtubule-driven spatial arrangement of mitochondria promotes activation of the NLRP3 inflammasome. Nat Immunol. 2013 May;14(5):454-60. https://doi.org/10.1038/ni.2550

9. Martinon F, Pétrilli V, Mayor A, Tardivel A, Tschopp J. Gout-associated uric acid crystals activate the NALP3 inflammasome. Nature. 2006 Mar;440(7081):237-41. https://doi.org/10.1038/nature04516

10. Ben-Chetrit E, Bergmann S, Sood R. Mechanism of the anti-inflammatory effect of colchicine in rheumatic diseases: a possible new outlook through microarray analysis. Rheumatology (Oxford). 2006 Mar;45(3):274-82. https://doi.org/10.1093/rheumatology/kei140

11. Nuki G. Colchicine: its mechanism of action and efficacy in crystal-induced inflammation. Curr Rheumatol Rep. 2008 Jul;10(3):218-27. https://doi.org/10.1007/s11926-008-0036-3

12. Reibman J, Haines KA, Gude D, Weissmann G. Differences in signal transduction between Fc gamma receptors (Fc gamma RII, Fc gamma RIII) and FMLP receptors in neutrophils. Effects of colchicine on pertussis toxin sensitivity and diacylglycerol formation. J Immunol. 1991 Feb;146(3):988-96.

13. Mollinedo F, Nieto JM, Andreu JM. Cytoplasmic microtubules in human neutrophil degranulation: reversible inhibition by the colchicine analogue 2-methoxy-5-(2',3',4'-trimethoxyphenyl)-

2,4,6-cycloheptatrien-1- one. Mol Pharmacol. 1989 Oct;36(4):547-55.

14. Das D, Pemberton PW, Burrows PC, Gordon C, Smith A, McMahon RF et al. Antioxidant properties of colchicine in acute carbon tetrachloride induced rat liver injury and its role in the resolution of established cirrhosis. Biochim Biophys Acta. 2000 Nov;1502(3):351-62. https://doi.org/10.1016/S0925-4439(00)00059-4
15. Al-Subaie AE, Laurenti M, Abdallah MN, Tamimi I, Yaghoubi F, Eimar $\mathrm{H}$ et al. Propranolol enhances bone healing and implant osseointegration in rats tibiae. J Clin Periodontol. 2016 Dec;43(12):1160-70. https://doi.org/10.1111/jcpe.12632

16. Moll JM, Wright V, editors. Psoriatic arthritis, semin arthritis rheum. City: Elsevier; 1973.

17. Holtrop ME, Raisz LG, Simmons HA. The effects of parathyroid hormone, colchicine, and calcitonin on the ultrastructure and the activity of osteoclasts in organ culture. J Cell Biol. 1974 Feb;60(2):346-55. https://doi.org/10.1083/jcb.60.2.346

18. Dudkiewicz I, Brosh T, Perelman M, Salai M. Colchicine inhibits fracture union and reduces bone strength: in vivo study. J Orthop Res. 2005 Jul;23(4):877-81. https://doi.org/10.1016/j.orthres.2004.11.014

19. Suyani E, Ozturk MA, Deger SM, Demirag MD, Goker B, Haznedaroglu S. Decreased bone mineral density in adult familial Mediterranean fever patients: a pilot study. Clin Rheumatol. 2008 Sep;27(9):1171-5. https://doi.org/10.1007/s10067-008-0930-0

20. Xu BB, Xu ZS, Zheng SL, Tang CR. Effect of colchicine on rat hepatic cytochrome P450 enzymes by cocktail probe drugs. Pharmazie. 2014 Jan;69(1):43-7.

21. Wang L, Shan Y, Chen L, Lin B, Xiong X, Lin L et al. Colchicine protects rat skeletal muscle from ischemia/reperfusion injury by suppressing oxidative stress and inflammation. Iran J Basic Med Sci. 2016 Jun;19(6):670-5.

22. Muriel P, Moreno MG, Hernández MC, Chávez E, Alcantar LK. Resolution of liver fibrosis in chronic $\mathrm{CCl} 4$ administration in the rat after discontinuation of treatment: effect of silymarin, silibinin, colchicine and trimethylcolchicinic acid. Basic Clin Pharmacol Toxicol. 2005 May;96(5):375-80. https://doi.org/10.1111/j.1742-7843.2005.pto_06.x

23. Liu H, Dong F, Li G, Niu M, Zhang C, Han Y et al. Liuweiwuling tablets attenuate $\mathrm{BDL}$-induced hepatic fibrosis via modulation of TGF- $\beta /$ Smad and NF- $\kappa B$ signaling pathways. J Ethnopharmacol. 2018 Jan;210:232-41. https://doi.org/10.1016/i.jep.2017.08.029

24. Lima V, Vidal FD, Rocha FA, Brito GA, Ribeiro RA. Effects of tumor necrosis factor- $\alpha$ inhibitors pentoxifylline and thalidomide on alveolar bone loss in short-term experimental periodontal disease in rats. J Periodontol. 2004;75(1):162-8. https://doi.org/10.1902/jop.2004.75.1.162

25. Souza DM, Prado FA, Prado MA, Rocha RF, Carvalho YR. Evaluation of two morphometric methods of bone loss percentages caused by periodontitis in rats in different locations. J Appl Oral Sci. 2010 Sep-Oct;18(5):493-7. https://doi.org/10.1590/S1678-77572010000500011

26. de Almeida JM, Theodoro LH, Bosco AF, Nagata MJ, Oshiiwa M, Garcia VG. Influence of photodynamic therapy on the development of ligature-induced periodontitis in rats. J Periodontol. 2007 Mar;78(3):566-75. https://doi.org/10.1902/jop.2007.060214 
The effect of colchicine on alveolar bone loss in ligature-induced periodontitis

27. Toker H, Balci Yuce H, Lektemur Alpan A, Gevrek F, Elmastas M. Morphometric and histopathological evaluation of the effect of grape seed proanthocyanidin on alveolar bone loss in experimental diabetes and periodontitis. J Periodontal Res. 2018 Jun;53(3):478-86. https://doi.org/10.1111/ire.12536

28. Leong NL, Hurng JM, Djomehri SI, Gansky SA, Ryder MI, Ho SP. Age-related adaptation of bone-PDL-tooth complex: Rattus-Norvegicus as a model system. PLoS One. 2012;7(4):e35980. https://doi.org/10.1371/journal.pone.0035980

29. Toker H, Ozan F, Ozer H, Ozdemir H, Eren K, Yeler H. A morphometric and histopathologic evaluation of the effects of propolis on alveolar bone loss in experimental periodontitis in rats. J Periodontol. 2008 Jun;79(6):1089-94. https://doi.org/10.1902/jop.2008.070462

30. Cai X, Li C, Du G, Cao Z. Protective effects of baicalin on ligature-induced periodontitis in rats. J Periodontal Res. 2008 Feb;43(1):14-21.

31. Koga T, Migita K, Kawakami A. Biologic therapy in familial Mediterranean fever. Mod Rheumatol. 2016 Sep;26(5):637-41. https://doi.org/10.3109/14397595.2016.1162261

32. Pascual E, Andrés M, Vázquez-Mellado J, Dalbeth N. Severe gout: strategies and innovations for effective management. Joint Bone Spine. 2017 Oct;84(5):541-6. https://doi.org/10.1016/i.jbspin.2016.10.004

33. Wang L, Chu X, Ma Y, Zhang M, Wang X, $\mathrm{Jin} L$ et al. A Comparative Analysis of Serum IgG4 Levels in Patients With IgG4-Related Disease and Other Disorders. Am J Med Sci. 2017 Sep;354(3):252-6. https://doi.org/10.1016/i.amjms.2017.05.009

34. Hoult JR, Payá M. Pharmacological and biochemical actions of simple coumarins: natural products with therapeutic potential. Gen Pharmacol. 1996 Jun;27(4):713-22. https://doi.org/10.1016/0306-3623(95)02112-4

35. Molad Y. Update on colchicine and its mechanism of action. Curr Rheumatol Rep. 2002 Jun;4(3):252-6. https://doi.org/10.1007/s11926-002-0073-2
36. Balli U, Cetinkaya BO, Keles GC, Keles ZP, Guler S, Sogut MU et al. Assessment of MMP-1, MMP- 8 and TIMP-2 in experimental periodontitis treated with kaempferol. J Periodontal Implant Sci. 2016 Apr;46(2):84-95. https://doi.org/10.5051/ipis.2016.46.2.84

37. Tüter $G$, Kurtiş B, Serdar M. Effects of phase I periodontal treatment on gingival crevicular fluid levels of matrix metalloproteinase-1 and tissue inhibitor of metalloproteinase-1. J Periodontol. 2002 May;73(5):487-93. https://doi.org/10.1902/jop.2002.73.5.487

38. Marcaccini AM, Meschiari CA, Zuardi LR, de Sousa TS, Taba M Jr, Teofilo JM et al. Gingival crevicular fluid levels of MMP-8, MMP-9, TIMP-2, and MPO decrease after periodontal therapy. J Clin Periodontol. 2010 Feb;37(2):180-90. https://doi.org/10.1111/j.1600-051X.2009.01512.x

39. Nahm DS, Kim HJ, Mah J, Baek SH. In vitro expression of matrix metalloproteinase-1, tissue inhibitor of metalloproteinase-1 and transforming growth factorbetal in human periodontal ligament fibroblasts. Eur J Orthod. 2004 Apr;26(2):129-35. https://doi.org/10.1093/ejo/26.2.129

40. Berkdemir Siverekli N, Sahin O, Senel S, Hayła E, Kaptanoglu $\mathrm{E}$, Elden $\mathrm{H}$. Bone mineral density in familial Mediterranean fever. Rheumatol Int. 2012 Aug;32(8):2453-7. https://doi.org/10.1007/s00296-011-1980-1

41. Bostancı V, Toker H, Senel S, Sahin S. Prevalence of periodontal disease in patients with Familial Mediterranean Fever: a cohort study from central Turkey. Quintessence Int. 2014 Oct;45(9):743-8. https://doi.org/10.3290/i.qi.a32442

42. Arai N, Ohya K, Kasugai S, Shimokawa H, Ohida S, Ogura $\mathrm{H}$ et al. Expression of bone sialoprotein mRNA during bone formation and resorption induced by colchicine in rat tibial bone marrow cavity. J Bone Miner Res. 1995 Aug;10(8):1209-17. https://doi.org/10.1002/ibmr.5650100811

43. Salai M, Segal E, Cohen I, Dudkiewicz I, Farzame $N$, Pitaru $S$ et al. The inhibitory effects of colchicine on cell proliferation and mineralisation in culture. J Bone Joint Surg Br. 2001 Aug;83(6):912-5. https://doi.org/10.1302/0301-620X.83B6.0830912 